\title{
Research on Landscape Conservation of the Traditional Villages of the She Nationality in Fujian Based on Ecological Wisdom
}

\author{
Jie Tian ${ }^{1, a}$, Hui $\operatorname{Pan}^{2, b^{*}}$ \\ ${ }^{1}$ Straits Institute of Minjiang University, Minhou, Fuzhou, Fujian, China \\ ${ }^{2}$ Graduate School of Minjiang University, Minhou, Fuzhou, Fujian, China \\ a308986977@qq.com \\ b*fjpanhui@126.com
}

\begin{abstract}
Under the background of ecological civilization, the current rural construction is confronted with the ecological dilemma. Deeply exploring, transferring and elaborating the contemporary value of traditional rural eco-wisdom will help ease the increasingly serious rural ecological crisis. The She village in Shangshui is one of the rare She villages, which is comparatively intact. It is also a typical vivid carrier of the ancient ecological landscape planning and construction system. Therefore, high research value and protection significance are there in this village. This paper is based on the combination relevant theories and concepts on eco-wisdom, landscape ecology and cultural landscape. Then it analyzes the characteristics of each section from the perspective of eco-wisdom by identifying the core components of the culture landscape in Shangshui She village, and is willing to provide a reference for the sustainable development of rural living environment. Keywords: Eco-wisdom, She (SH), landscape, protection
\end{abstract}

\section{基于生态智慧的福建畣族传统村落景观保护研究}

\author{
田洁 1 , a 潘辉 $2, \mathrm{~b}^{*}$
}

${ }^{1}$ 闽江学院海峡学院, 闽侯, 福州, 福建, 中国

2 闽江学院研究生处, 闽侯, 福州, 福建, 中国

a308986977@qq.com

$b^{*}$ fjpanhui@126.com

\section{摘要}

生态文明的背景下，当前乡村建设面临着生态的困境，挖掘传统的乡村生态智慧的当代价值，加以转 换和再诠释, 可缓解日益严重的乡村生态危机。上水畣村是少有的保护较为完整的悆族村落, 是比较 典型的具有古代生态景观规划和营建体系的鲜活载体，具有较高的研究价值和保护意义。文章结合生 态智慧、景观生态学、文化景观的相关理论和概念, 通过识别上水畜村村落文化景观核心构成要素, 在生态智慧视角下分析各个斑块的特点, 以期能为乡村人居环境的可持续发展提供参考。

关键词: 生态智慧, 墖族, 景观, 保护

\section{1. 前言}

畜族原本是广东东部最大的族群, 现在主要分布在 福建、浙江、江西、安徽等省份山区。在全国第四次人 口普查中, 福建畣族人数约占全国畣族人数的二分之 一, 主要分布在闽东宁德地区, 几乎占福建省畣族的一
半。畣族是较为典型的散居性民族, 世代多是以农耕为 生, 福建的畜族村落较为集中在丘陵地带, 里面丘陵密 布, 山峦起伏。㓱族的文化在历史不断的迁徙过程中, 积累了深厚的文化底蕴, 但是在当代, 畣族的传统文化 仍限于在本族人中传承发展, 近年来, 福建省响应国家 政策，积极推进美丽乡村建设，因此，对于會族传统文 化继承和创新迫在眉睫。关于墖族的研究, 有学者对畣 
族的 “凤凰装” 样式进行研究，也有对畜族的传统村庄 聚落形态以及文化的传承进行研究。这些大多是悆族聚 落或者文化保护的管理模式、技术和乡村聚落的开发利 用模式等方面的研究。另外一部分是对畜族村的景观规 划与设计的研究, 主要涉及的重点是进行景观设计的理 论研究或是新的景观规划设计案例实践研究。本研究是 从生态智慧的角度出发, 以福建省霞浦县典型畜族聚居 村上水村的景观体系作为研究对象，通过景观基质、 文化景观要素几个层面分析上水愈村的传统景观营造 的生态智慧, 研究上水畣村生态智慧对于丰富少数民族 乡村聚落景观营造以及保护理论，运用现代生态手法辅 助避免上水畜村景观斑块破碎化, 也为传统乡村的建设 提供较为有价值的参考。

\section{2. 生态智慧解析}

生态智慧源远流长, 《周易》讲述了天、地、人三 才之道, 这种哲学思想贯彻中华民族文化之中, 被认为 是具有生态和谐亦或平衡的思想理念, 体现出了最早的 生态直觉。道家提出了以 “道”为核心的生态哲学思想 的框架体系; 儒家提出以 “善” 为核心的 “仁者爱人” 的哲学思想, 构建了带有生态思想的伦理型哲学体系。 这些上千年的中华智慧观, 深深影响着社会的发展, 在 现代乡村景观生态危机面前仍然具有重要的启示和借 鉴作用。二十世纪七十年代挪威著名的哲学家阿伦 - 奈 斯 (Arne Nasess) 提出了生态智慧 (Ecological Wisdom) 的概念, 这是首次在生态学的领域融入了哲学思想和伦 理学, 提出生态自我、生态平衡与生态共生的深层生态 学 (Deep Ecology) 的理论框架体系。奈斯为后来生态 智慧的研究抛出了一个深刻命题与思维指向: 首先, 生 态智慧是从整个生态系统的角度出发来探讨人与自然 之间的价值导向问题; 其次, 生态智慧意图通过最低程 度的人工介入寻求人居环境与生态系统的最优平衡方 案, 从而获得最大的生态效益; 第三, 生态智慧强调生 物多样性、文化多样性、行为多样性以及风格多样性。 【1】

关于运用生态智慧如何解决生态环境问题, “生态 智慧与城乡生态实践” 同济论坛 (2016) 正式展开了关 于生态智慧和城乡生态实践相关研讨, 重要学术成果之 一是《生态智慧与生态实践之同济宣言》, 在人与天的 生态智慧引领下, 深入挖掘生态智慧与生态实践的内涵 与价值, 共同探讨不同地域文化背景下的生态实践, 分 享生态智慧对人居环境可持续生态实践的启示。生态智 慧是长期的生态生活实践中运用聪明才智总结出来的 经验智慧, 它具有客观性和合理性, 其在本质上就是人 类的生存智慧艺术。同时, 与乡民时代传承下来的尊重 所有生命形式和土地的哲理不谋而合。

\section{3. 研究对象概况}

上水村位于海拔 350 多米的福建省霞浦县西北山区
的崇儒畜族乡的中部, 是目前较为少见的纯畜族村寨, 村落的地理条件优越, 地域是典型的山地丘陵地貌, 丘 陵连绵山岭起伏, 溪流纵横, 植被繁茂。古村周边有悆 族樟坑大厝、国家地质公园太姥山、葛洪山、朱喜讲学 处等众多的自然人文景观。村落建筑目前保留着较为完 好的墖族古民居，依山建房、聚族而居、自成村落，是 目前福建传统畒族民居保存最完整的村寨之一。

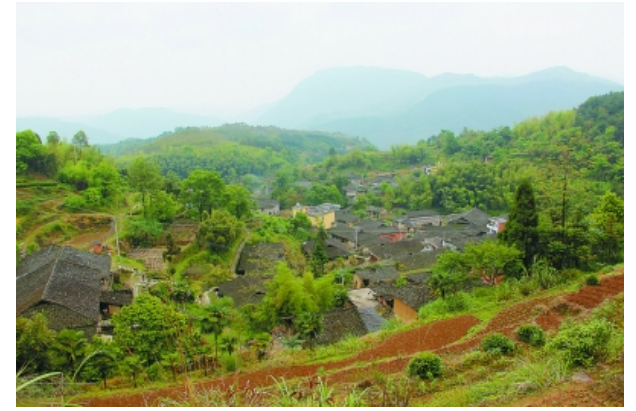

图 1 上水村俯瞰景观

\section{4. 會族传统村落景观的生态智慧}

\section{1. 畜族传统村落景观基质的生态智慧}

\section{1. 1. 自然环境基质}

上水㓱村始于明代，距今已有近四百年的历史，村 落选址的地理条件优越, 属于中亚热带海洋季风湿润气 候区, 雨量适中, 年降水量为 1359.5 毫升, 四季分明, 光照资源丰富, 年平均气温为 $17.83^{\circ} \mathrm{C}$ 。地貌特征为典 型的山地丘陵地貌, 层峦叠嶂, 溪流纵横。清代光绪年 间编撰的《汝南郡蓝氏房谱》记载，明崇祯九年（1636 年）, 蓝姓始祖齐满公从浙江泰顺县沙丘田寻至此地, 见到一处悬崖上有块岩石, 上崖流水直冲到岩石上, 就 像银树花开, 而岩下潭内不见水注花, 仅能听到嘈嘈声, 就给它取名为 “水漕垅”，“2】后改名 “上水”，取名 自上善若水，出自老子的《道德经》“上善若水，水 善利万物而不争。” 寓意最善的人好像水一样, 水善于 滋润万物而不与万物相争。又看到西面有小溪绕山穿石 蜿蜒而来, 汇集在此后向东南流去, 其形态如同 “Y” 字。背山可以屏挡冬日北来寒流; , 面水可以迎接夏日 南来凉风; 朝阳可以争取良好日照; 植被可以保持水土、 调整小气候; ${ }^{\mathbf{I} 1}$ 这是是典型的景观阴阳风水的优秀的 选址, 上水村畣族祖先深谙景观阴阳学说, 好的选址会 在农、林、牧、副、渔多种经营中产生良好的生态循环， 良苦用心选址在此, 体现了他们特有的生态智慧。

\section{1. 2. 人文环境基质}

上水會村由于畣族人口居多，部分汉族的村民也被 同化，整个村寨里薈汉两族村民不论男女老少都是用畣 
话交流, 是较为罕见的生态峹寨。目前村寨仍保留着淳 朴的民风、勤劳的畣民，浓厚的墖族文化底蕴。同时， 上水墖村具备少有的原生态畣族村寨人文建筑景观。村 寨的石屋寨独具特色, 是传统畣族村石文化的典型代 表。这种石屋寨最早追溯于齐满公的祖训: 凡后代劳动 收工, 必须扛着石头回家, 修整溪岸。搬石建村的祖训, 让先民们住上了石头和土木结合的村屋。这种石屋就地 取材, 将地形地貌与规划格局融为一体, 具有丰富的空 间层次关系, 在空间尺度上节奏紧密, 内聚外松, 这反 映出了尊重自然的生态智慧。

\section{2 畜族传统村落景观斑块的生态智慧}

根据文化景观的定义, 上水墖村的文化景观的组成 要素含物质文化景观要素和非物质文化景观要素。从构 成要素和功能方面进一步划分, 物质文化景观分为农业 生产斑块、村屋聚落斑块、水文景观斑块; 非物质文化 景观分为宗教文化类斑块以及经济社会类斑块。文章从 空间尺度上对畣村文化景观的生态智慧进行分析。

\subsection{1. 物质文化景观}

上水墖村的内部景观格局呈现为以 “ $Y$ ” 字交叉点 为中心, 向三面扩展。以山体、公路为會村的边界, 溪 流从村落当中穿过把村落建筑划分为三大块, 以村屋和 农田为景观斑块, 这种布局, 便是源于祖先 “规划” 的 景观格局。

\subsubsection{1. 农田景观斑块}

畣村的农田斑块比较集中在山坡上比较平缓的地 带和㓱村周围开阔的地带, 同时与古村屋形成了斑块镶 嵌的景观格局。根据不同的区位分为山地农田和川水农 田。耕作的格局模式主要分为梯田耕作、大田耕作、小 田耕作。【 ${ }^{4}$ 大田耕作一般是在川水农田, 每家根据自 家的需求种植不同的农作物, 分配种植在不同的地段。 小田同样在大多分布在川水农田, 跟大田交错种植, 形 成大小不一的田块, 作物的种类丰富, 由于上水墖村在 丘陵地带, 田地的周围林地密布, 林地与田地元素交融, 在小区域内维持了较高的生物多样性, 同时, 通过集水 线将山上的水顺应地势汇集到下面的坑塘水系进行收 集存储。梯田是上水㓱村独具特色的农田肌理, 梯田根 据等高线分布, 田块面积较小, 大多会种植福建本地茶 树，形成茶文化的梯田景观。

农田斑块根据地形地势进行种植, 形成“自然衍生” 的布局形式, 没有明显的中心, 整体呈现出 是自然随 意的布局状态。这是上水畣村遵循着 “与地形结合, 顺 应自然” 的原则, 营造的 “天人合一” 的农田景观环境, 这些自然形态, 包括 “Y” 字溪流干旱时引水浇灌农作 物, 满足农田浇灌的需求, 都是自然的各个元素进行互 补, 农作物亦选用适宜本地种植、适宜时节种植的作物,
可以循环养分保持土壤肥力的有机农田，尊重自然，不 削山挖水, 刻意造田, 对畣村的山体、水系等生态环境 起到保护作用。

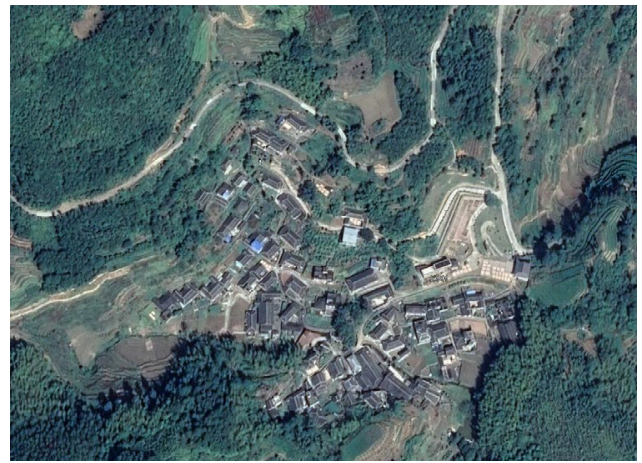

图 2 农田斑块景观

\subsubsection{2. 苓村民居聚落斑块}

上水畣村的建筑形态保存完整, 临溪聚居, 沿路筑 厝，依山筑村。前排的民居临溪聚居，后面的民居根据 地形等高线逐层建设, 错落有致, 形成了朴素的畣族村 聚落景观面貌，具有完整性、真实性以及延续性，体现 了 “裁成天地之道, 辅相天地之宜” 的古代生态智慧。 在造址之初, 就充分考虑了禁建、适建以及限建的原则, 对于地质活跃区进行合理避让，长期居住生活至今，这 些都是先民避灾和适应灾害的生态智慧。

古民居的围墙及护坡，沿街两岸以及村道均是采用 毛石砌成。这种独具特色的村落建筑景观源于畜族祖先 齐满公对于自然的敬畏, 他要求后代们沿着小溪开荒取 地, 在山上劳动结束取石修整溪岸, 这是对水的敬畏感。 经过几百年的修整和先民自己的生态智慧, 通过早期的 青石溪岸延伸到青石墙、青石屋、青石铺路等。这种低 成本、低技术的建造体系形成的独具上水畬村风貌的村 落特征, 同时体现了环保的生态智慧。

另外, 水元素是与上水墖村民居紧密结合的元素之 一。上水㓱村先民借助水流冲击的惯性, 让河床冲击的 地方淤泥不断积聚，从而扩大宅基地的面积。同时，为 防止强降雨时期对民居的冲击，雨水通过坡屋顶的房檐 汇聚到院落, 再通过石板铺地自然下渗, 民居空间两侧 均设计有排水沟渠形成完善密集的雨洪网络, 这种因势 建房、增蓄减排的方法, 是值得学习的理水排涝以及治 水防洪的生态智慧。

\subsubsection{3. 水文景观斑块}

传统的景观风水学说理论认为 “风水之法, 得水为 上”，“吉地不可无水”。水塘能 “聚水养气”; 从生 态实践的角度来看, 水塘能起到泄洪灌溉、减缓流速、 蓄水利用的作用, ${ }^{51}$ 水系是上水墖村与其他村落景观 基质联系的通道, 挖塘蓄水是上水畜村进行水系改造的 生态实践。水系在上水畒村与农田、山体形成了山水田 格局，激发了山水田格局的各个生态因子，水是农田形 
成的首要因素, 先民通过结合上水村的生态规律和水文 分布, 通过结合地形引水灌溉、稻田养鱼、挖塘蓄水、 石板铺地自然下渗、排水明沟分流排水、水在排放和下 渗过程中得到净化和利用等原始水生态模式建立了水 源的引用、渗透、灌溉、蓄水、分流、净化各个环节, 符合了海绵城市建设的几大要素, 形成了顺应自然、利 用自然、维护水生态环境的有机循环的生态系统, 这是 上水畣村的水生态智慧的结晶。

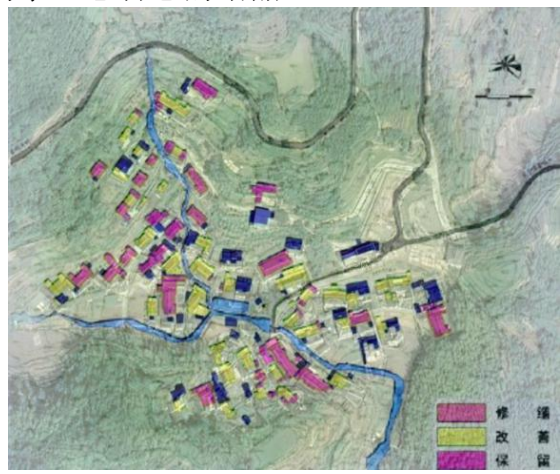

图 3 水文景观斑块与民居聚落斑块关系

\subsection{2. 非物质文化景观}

\subsubsection{1. 文化宗教景观斑块}

上水畜村保留着浓厚的民族特色的非物质文化遗 产, 主要有宗教信仰、民俗活动、民间技艺和特色饮食 等方面。

畣族乡民崇宗敬祖, 也具有多神信仰习俗, 体现供 奉天有 “天公”、地有 “土地公”、田有 “民主公”、 山有 “山神”、水有 “龙王” 等。同时上水畜村具有最 为典型的几种畣族特色文化, 形成自己的风格, 例如: 香族花斗笠、畣族服饰手工刺绣、二月二、三月三传统 畣歌会。其中村中的 “畣族花斗笠” 和 “手工刺绣畣族 服饰” 的传统工艺远近闻名。上水村的传统美食 “畣族 菅叶粽” 和 “畣族糍粑” 获得两项县级非物质文化遗产 名录。【 61 可以看出, 上水㓱村不仅孕育了独特的村落 空间, 同时也孕育了具有场所精神的文化生活空间。通 过对㓱族文化、宗教的传承, 唤起空间记忆和活力, 唤 起乡村文化自觉, 对于逐渐遗忘的文化碎片和记忆碎 片, 进行梳理和保护传承, 留住乡愁记忆。

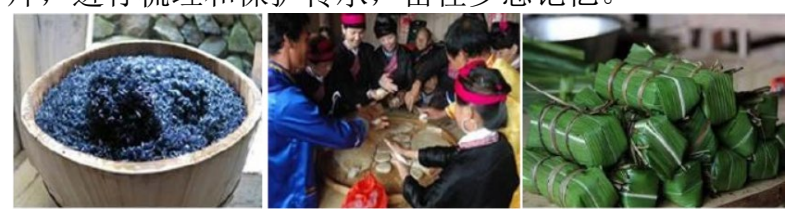

图 4 上水墖村特色文化

\subsubsection{2. 社会经济类景观斑块}

畜村充分开发畣族传统工艺品、特色饮食等产品,
建立上水畜族品牌，通过电商等形式提升乡民的收入水 平, 带动畣村经济的发展。另一方面, 上水墖村充分发 挥其独特的物质景观优势, 通过观光游览、农家乐的形 式发展墖村特色旅游业。提升传统农业，保护畣村特色 梯田景观, 结合茶文化做创意梯田, 增加农事活动体验, 绿色农产品种植，提升乡民的收入。

\section{5. 基于生态智慧的上水會村景观保护策略}

\section{1. 强化生态㓞性, 削弱胁迫因子}

上水畣村的保护以其稳定的生态安全格局为保障, 充分运用生态智慧的理论, 进行适度的人工干预, 目前 畣村面临的是雨洪、内涝等胁迫因子，可以通过在地质 活跃区丰富本地树种，同时在林地优化生物群落的结 构, 从而丰富植物的群落层次以及物种的多样性, 进而 减少山体滑坡、洪涝灾害, 增强生态的涵养能力, 最终 达到健全生态体系的目的。另外，通过 GIS 等软件对上 水㓱村的土地进行评估, 用量化的方式分析最优的生态 途径,

优化生态基质、生态斑块、生态廊道，丰富廊道的 传输功能、生境功能、连接功能, 打造具有浓厚畣族特 色的智慧型传统村落。再有便是保护水环境的智慧性, 保护水环境生态型, 提升水环境的韧性, 通过运用新的 生态水环境治理手段, 结合传统水环境智慧, 为上水㓱 村提供弹性、兼容和张力的能力。

\section{2. 完善上水畜村文化景观体系}

从时间尺度上看，上水墖村的文化景观斑块仍然呈 现破碎化发展的趋势, 斑块内部的景观多样性也有所降 低。来源于外力的新农村建设和来源于内部的自身的传 承意识薄弱, 使得社会、生产功能弱化和转变, 景观组 成元素和景观空间分布的丰富性大打折扣, 随着景观内 部的异质性降低，也将加速民居聚落斑块的消失。上水 㓱村的传统生态实践智慧, 同样反映出了传统少数民族 村落体系所具有的文化景观潜力, 其 “低冲击、低碳、 低成本、低干预” 的景观营建和保护哲学是现代城市景 观设计追求的目标之一。因此需要重视和完善其传承几 百年的文化景观营建生态智慧体系, 对其认知和保护, 用乡村文化自觉来激发文化自信。运用生态智慧理论指 导当代其他传统村落生态智慧实践, 营造可持续的乡村 居住环境。

\section{References}

[1] Xin, HR., Zeng, J, (2019) Research on the protection of traditional villages in the mountainous areas of southwest China based on ecological wisdom. Chinese landscape architecture. 35: 95-99. 
[2] Ai, XP, China(2015)Travel to xiapu taste shitou village in the she style,http://blog.sina.com.cn/s/blog_156dd58700102w6oq. html

[3] Wang. QH. Etc(2005)The composition of Chinese geomantic pattern, ecological environment and landscape. In: Shang. K. (Eds.), Research on geomancy theory. Tianjin university Press., Tianjin. pp. 37-43.

[4] Wang, GP, Min, QW, Xue, DY, (2019), Tu nationality traditional culture village landscape and its change. Heritage and protection research,4: 57-64.

[5] Cai, J.J, (2019) Ecological wisdom of water control in traditional villages in southern fujian and its contemporary enlightenment. Journal of changchun normal university.,38: 105-109.

[6] Ren. WY. China(2018)Xiapu chongru shangshui she village,https://baijiahao.baidu.com/s?id=16189073716098 89344 